\title{
Spatial Treatment in Children's Drawings: Why Do Japanese Children Draw in Particular Ways? \\ Masami Toku
}

\section{Introduction}

In the study of children's artistic development, there are two main issues: one is universality in the pictorial world (pictorial presentation, composition. spatial treatment, and so on); another is called non-universality, which is socialcultural influences which appear in children's drawings (See Examples, Alland, 1983; Arnhein, 1954, 1969; Golomb, 1992; Goodnow, 1977; Kellogg, 1969). The debate has been over which is predominant in children's development; however, the debate is no longer meaningful because we do not doubt that these two issues interact strongly. The debate in artistic development should be what kinds of social-cultural influences tend to emerge depending on the particular culture based on the universality in the pictorial world with children's physical growth (motor skills) and cognitive development (cognitive abilities).

The purpose of this study was to examine what kinds of social-cultural influences tend to emerge in the spatial presentation of children's drawings depending on the particular culture. How and why such particular social-cultural factors influence children's cognitive development was examined to consider a proper art curriculum to support children's cognitive development by understanding the effect of cultural and social influences on children's visualspatial abilities. If cultural and social backgrounds affect children's cognitive development positively or negatively, it is crucial to consider the kinds of art curricula that should be developed to help children's visual thinking skills reflect cognitive development, by examining the effects of social-cultural factors.

This paper is divided into three parts: 1) the importance of studying spatial treatment in children's drawings; 2) the reviews of the pilot study of crosscultural analysis of Japanese and US children that I did from 1993 through 1995; 3) Japanese children's characteristics in the spatial treatment from 1996 through 1997.

\section{The importance of studying spatial treatment in children's drawings}

As human abilities of cognition, how infants start to perceive depth and how they experience space as three-dimensional are fascinating subjects in developmental psychology. In the study of artistic development, how children start to draw space/depth on two-dimensional surfaces, such as paper, a wall. the ground, etc., and develop technique $s$ of spatial presentation that allow them to depict relationships in a realistic manner is an important subject in the study of drawing.

We live in a three-dimensional world. We are able to perceive depth, length, and height without learning how to perceive these qualities from others.

Marilyn Zurmuehien's Working Papers In Art Education 1996-1997 
In addition, with physical growth (motor skills) and mental growth (cognitive abilities), infants start to scribble and eventually create their own pictorial worlds in drawings. In the process of creating a pictorial world, we can see a developmental direction in spatial presentation in children's drawings. How do children know how to create space/depth on flat surfaces by using techniques such as relative size, relative density, relative position, overlapping, and, finally, linear perspectives? Do children invent such techniques by themselves or learn from someone else -parents, teachers, peers, or visual models? is there a universality in the process of creating space on two-dimensional surfaces? When and how do social and cultural influences appear in spatial presentation in children's drawings? Which is dominant, universality or non-universality (culture specificity), in children's drawings? Does this dominance shift with age?

Although we take for granted the possibility of creating convincing illusions of space on two-dimensional surtaces, we have to realize that the techniques used to create space were just invented after the Renaissance period, in the fifteenth century. Until the Renaissance period, even adults who were artists did not have such techniques to create space on two-dimensional surfaces. Did children living in the fifteenth century know the techniques, although adults did not know? It seems unlikely. It is easy to imagine that there should be some differences between the drawings of children in the twentieth century and children in the fifteenth century and in the ways children create space, although we have few records of children's drawings in the fifteenth century. Furthermore, the new methods of creating space in the Renaissance period were just spread over Western world of Europe in those days. In Asia Africa, Australia, and other areas, artists invented and used other techniques to create space on two-dimensional surfaces. For example, it is well known that Japanese artists created a new technique in the fourteenth century called "a bird-eye's view (looking obliquely down from sky like birds when they are flying)" to express space/depth on two-dimensional surfaces such as screens, hanging scrolls, and sliding doors. How and when universality and non-universality are interwoven in the process of creating space in children's drawings is an interesting and important subject in the study of artistic development.

\section{The pilot study of cross-cultural analysis of artistic ability between US and Japanese children (1993-1995).}

In a pilot study for Cross-cultural Analysis of Children's Artistic Development, about 1,000 drawings were collected from mainly two populations in Chicago and Champaign, and two cultures, which were Japanese and US children from 2nd, 4th, and 6th grades. There were significant differences in spatial development for the two populations as a result of analysis based on Eisner's 14 categories that he constructed in 1967 to see the differences between advantaged and disadvantaged children in the US (Eisner, 1967. 1972).

One difference is the speed of spatial development. In moving from one category to another, Japanese chiidren are faster than US children and they showed a tendency to choose more complicated methods of creating space in 
their drawings than did US children. The reason is seemingly obvious. Unlike art education in the US, Japan has adopted a national curriculum, which means no matter where they are born, Japanese children have to take art class as a required course as well as other subjects from 1st through 9th grade during the compulsory educational period. It is easy to imagine how the art educational curriculum encourages Japanese children to develop their artistic ability.

I also found that Japanese children seemingly use some unique patterns when they create space, which US children seldom use. Actually, more than $20 \%$ of Japanese children's drawings could not be classified into Eisner's categories. although less than $5 \%$ of US children's drawings could not be classified into the categories. Then what kinds of techniques do Japanese children use? I found at least 3 patterns: bird-eye's views, exaggerated views, and multi-perspective views (Toku, 1995, 1996).

However, it was too early to conclude that these were exactly Japanese children's characteristics since the drawings examined were collected from Japanese children who lived in Chicago, not in Japan, due to their parents' employment. To determine whether the patterns are really unique to Japanese children in elementary schools, I decided to develop this study to identify the socio-cultural influences that are responsible for the early emergence of these characteristics.

\section{Why do Japanese children draw in their own ways? (1996-1997)}

To find what kinds of socio-cultural factors actually influence the characteristics which appear in Japanese children's spatial treatment in drawings, in this study two tasks were given (drawing and judgment tasks) with the following hypothesis:

\section{Hypothesis}

1. There is a direction of development in spatial treatment in Japanese children's drawings regardless of areas in Japan.

2. There is a valid artistic developmental stage theory which can describe a qualitatively equal shift from one category to another in spatial treatment.

3. There are no unique patterns of creating space in Japanese children's drawings -- Bird's-eye view, Exaggerated view, Multi-perspective view, etc.

\section{Drawing task}

About 2,500 drawings of 1 st through 6 th grade Japanese students who studied under the Japanese nationa curriculum were randomly selected from three areas (northern, central, and southern parts of Japan) to confirm whether characteristics which appeared in drawings are really particular to Japanese children. Japanese children drew the same subject as in the pilot study, "My friend \& me playing in the school yard," a theme investigated in an earlier study 
Figure 1: Eisner's $1+$ Categories of Spatial Treatment in Children's Drawings
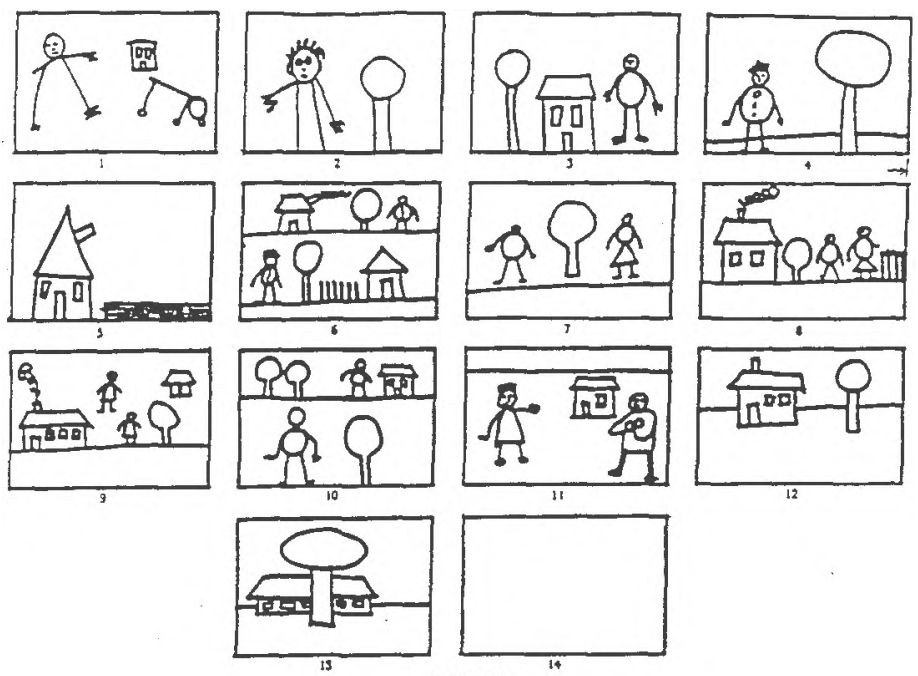

nCURe I

VTSUAL DOEMPLAR OF EACH CATLCORY

Category 1: No horizon line present. Morphemes "floating." not standing on edge of paper. Category 2: Morphemes standing of bottom-edge of paper. No horizon line drawn.

Category 3: Some morphemes standing on bottom-edge of paper, others floating in space.

Category 4: Morphemes standing on bottom edge of paper and horizon line drawn.

Category 5: Partial horizon line drawn.

Category 6: Two or more horizon lines drawn

Category 7: Horizon line drawn. Morphemes floating above horizon line.

Category 8: Honzon line drawn. Morphemes standing on horizon line.

Categon: 9: Horizon line drawn. Some morphemes standing on horizon line. others floating above horizon line.

Category 10: Morphemes overlap ground but do nor overlap horizon line.

Category 11: Morphemes standing on bottom edge of paper and overlap borizon line

Categon. 12: Horizon line drawn. Morphemes clearly overlap horizon line.

Category 13: Horizon line drawn. Morphemes overlap each other.

Category 14: Linclassifiable. 


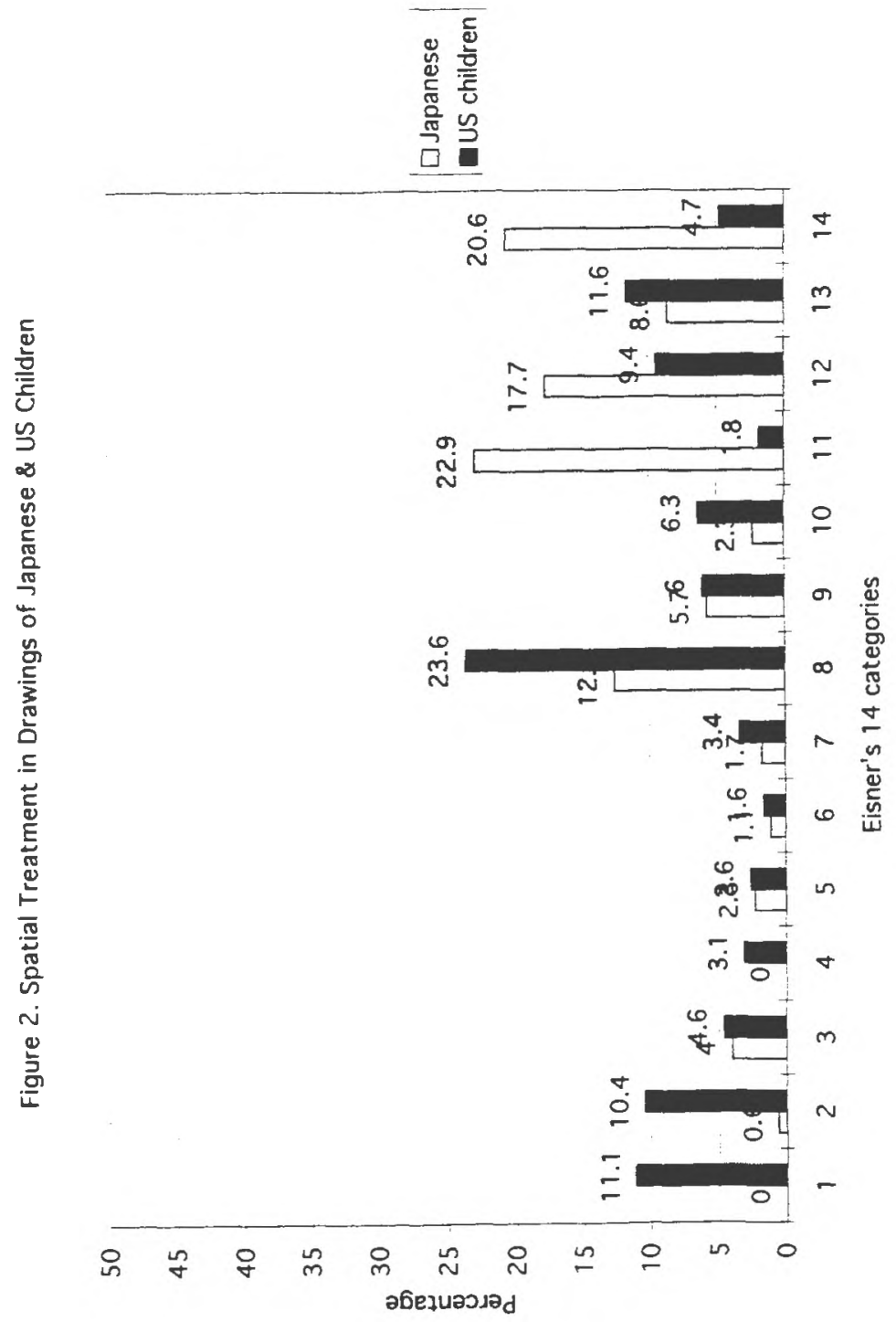

Marilyn Zurmuehlen's Working Papers In Art Education 1996-1997 
by Elliot Eisner (1967). First, Eisner's 14 spatial categories were used to classify the spatial similarities and differences of Japanese children's drawings with the statistical method, Chi-square. The result was that all three hypotheses were rejected. This means that Japanese children do not develop from one category to another based on Eisner's spatial categories and there is not a concrete direction of the development of spatial treatment in children's drawings. However, at the same time, we can see the same tendency found in the pilot study appear in three areas of Japan, as more than $30 \%$ of Japanese children drawings could not be classified in Eisner's categories. This indicates that Japanese children clearly have some unique patterns when they create space on 2-D surfaces.

The drawings were then reclassified according to Toku's 20 categories (1997) (which were constructed based on Eisner's 14 categories) to classify spatial presentation in Japanese children's drawings. These new categories were developed to categorize Japanese children's unique patterns of spatial treatment that could not be classified by Eisner's 14 categories. However, these do not a form spatial scale to show a developmental direction since children do not always shift from one to another category with their age. These categories are mainly composed of 8 concepts: 1. Mapping (category 1), 2. Alignments without a ground line (categories 2 through 4), 3. Alignments with a ground line (categories 3 through 10), 4. More than two ground lines (categories 11 and 12), 5. Open space (categories 13 and 14), 6. Photographic \& exaggerated views (categories 15 and 16), 7. Bird's-eye views (categories 17 through 19), and 8 . Multi-perspective views (category 20). Regardless of which of the three areas in Japan, children showed a tendency to often use complicated techniques of creating space considering their ages, such as photographic and exaggerated views in spite of the fact that younger students (1st and 2nd grade) chose alignment techniques when they created space due to their lack of skills rather than their lack of knowledge of the concept of space.

\section{Judgment task and observation}

The judgment task was implemented by asking six questions based on seven different types of spatial drawings to confirm the relationship between children's knowledge of depth and their actual drawings. About 1,000 pieces of data were randomly collected from the same three areas in Japan and analyzed to determine the correlation between children's cognitive development and their preference for drawings.

The following six questions were asked: 1 . Which picture is the best in showing spatial depth? (Which picture is the best in showing the relationship of far and close?); 2. Which picture is the worst in showing spatial depth?; 3 . If you were to draw a forest scene, which picture is the closest to the one that you would draw?; 4 . If you were to draw a forest scene, which would you never draw?; 5. which is your favorite picture?; 6 . Which is your least favorite picture? The first two questions were to determine students' knowledge of space. The third and fourth questions were to find their actual drawings when they drew spatial scenes regardless of their knowledge of space. The fifth and sixth questions were related to aesthetics rather than drawing preference. These questions were given in 


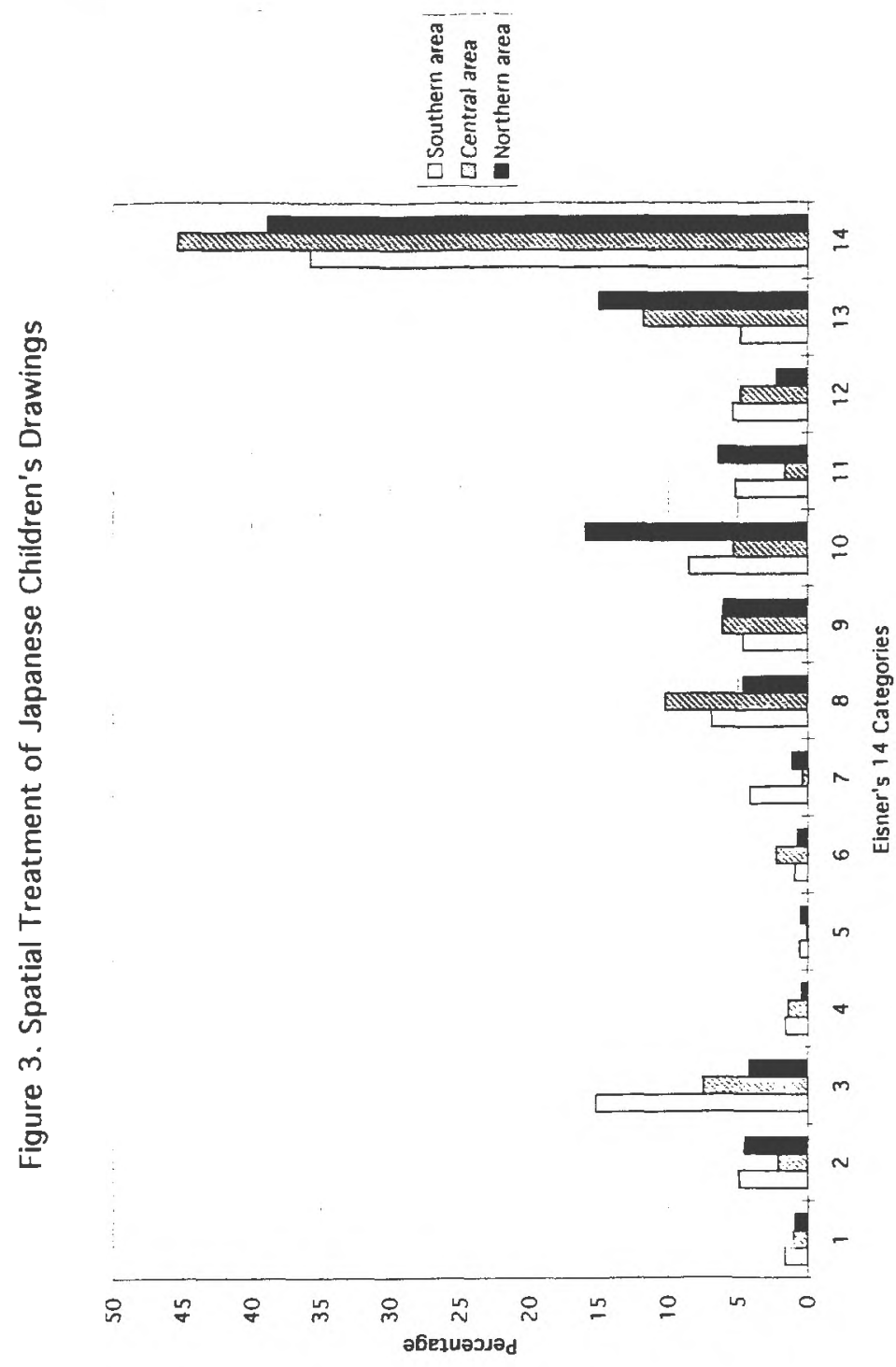

171

Marilyn Zurmuehlen's Working Papers In Art Education 1996-1997 


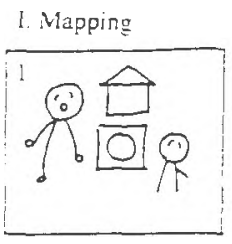

II. Alignment without a ground line
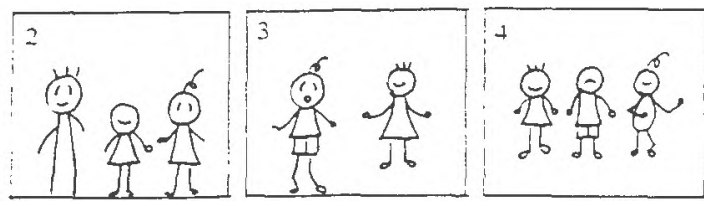

is ith a ground line
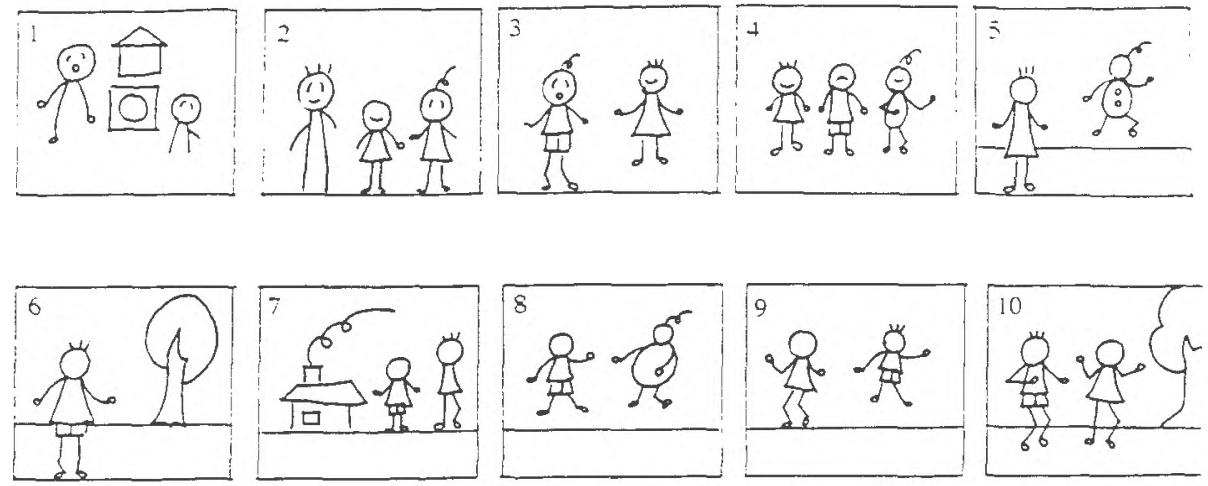

(with two ground lines)
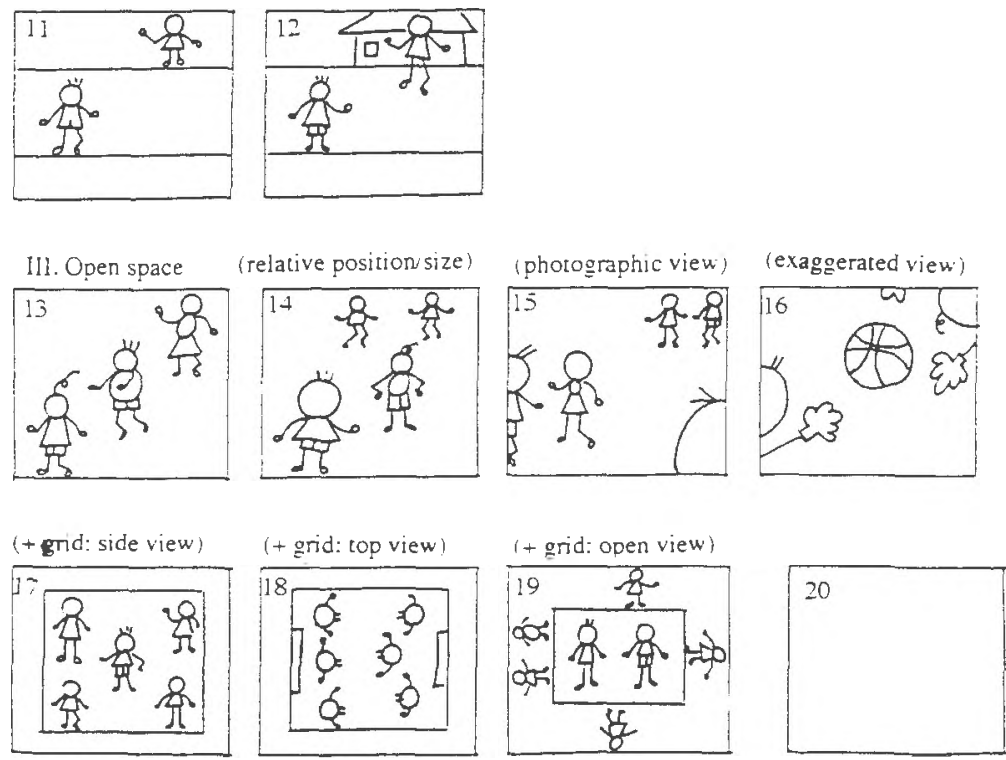

172 


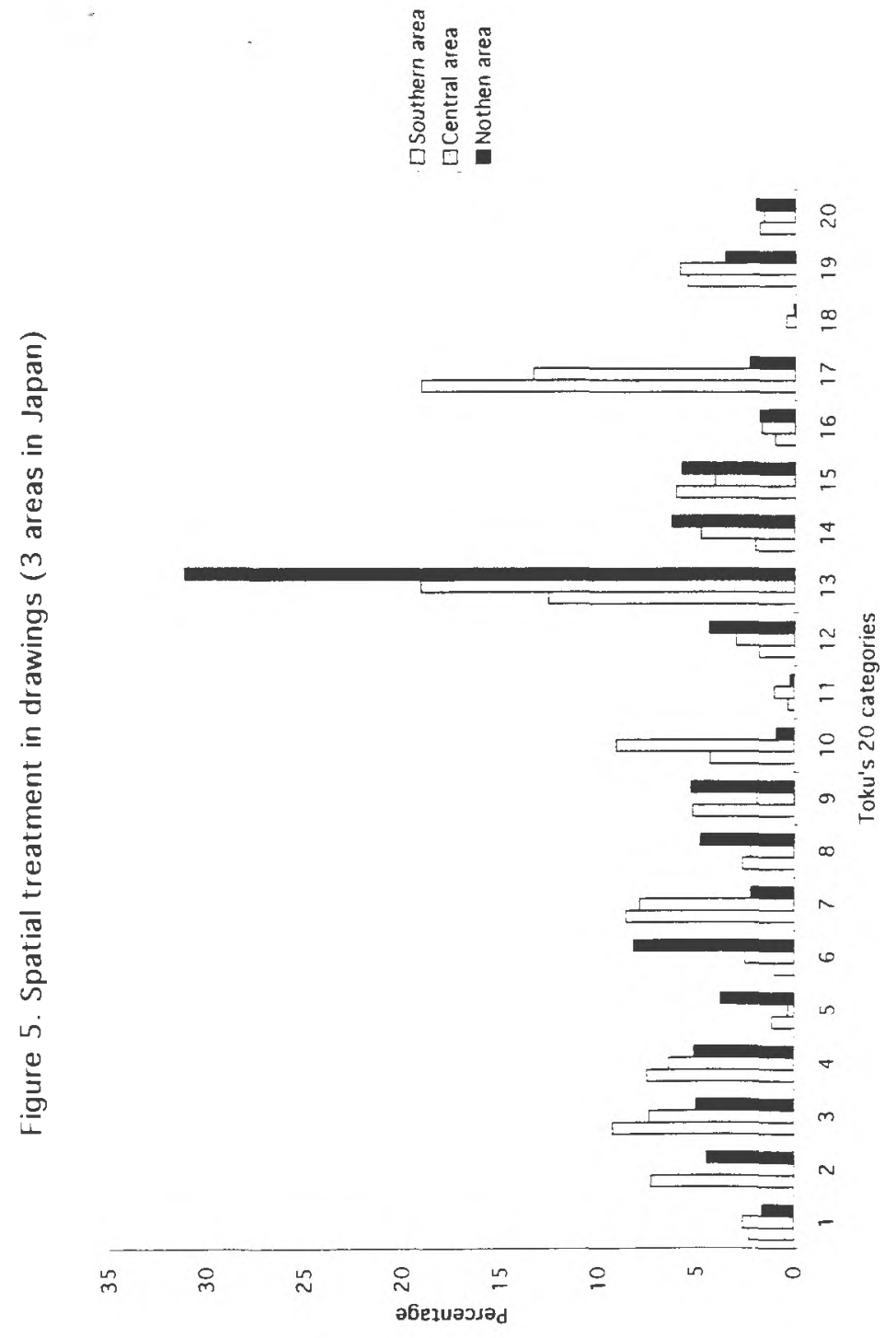


7 Different Types of Pictures for Judgment Task
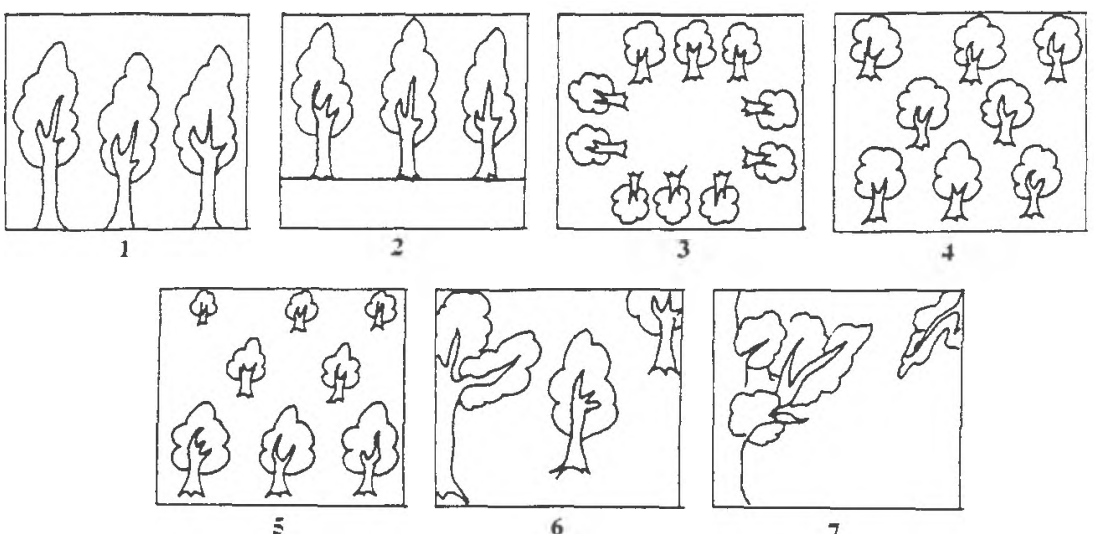

Questions for Judgment Task

Question 1: Which picture is the best in showing spatial depth?

(Which picture is the best in showing the relation ship of far and close?)

Question 2: Which picture is the worst in showing spatial depth?

Question 3: If you were to draw a forest scene. which picture is the closest to the one that you would draw?

Question 4: Which would you never draw'?

Question 5: Which is your favorite picture?

Question 6: Which is your least favorite picture? 
different ways depending on their ages to make sure of their understanding of these questions' meanings. For each question, students were allowed to select one number and wrote which they chose among seven drawings (if students did not understand the meaning of the question, they were allowed to select the 8th number) without discussing it with anyone. At the same time, students' reactions to these questions were observed.

In response the first and second questions, there was a big difference between 1st graders and the rest of the grades. According to the data, 1st grade students' responses were spread over six pictures, which suggests that they did not have the concept of space. In addition, 10 to $15 \%$ of 1 st grade students responded that they did not understand the meaning of the first and second questions. However, most students already tend to have the concept of space before reaching 2 nd grade. In the 3rd and 4th questions, students' actual drawings shifted from the alignment type of drawings to more complicated spatial drawings, such as picture six (photographic picture) and seven (exaggerated view) with their ages. In spite of the fact that most students, regardless of their age, show their preference for the number five (relative-size picture) or six pictures, younger students tend to choose the technique of number one and two (alignment pictures without and with a horizon line) when they draw. This indicates that students have a tendency to draw at that their own skill level rather than their preference. In the final 5th and 6th questions asking their aesthetic preference, more than twenty percent of all students selected the exaggerated view (picture six) as their favorite picture, and they selected the open-box view's picture (picture three) as their least favorite picture. Despite students' aesthetic preferences, their actual drawings show their ability and limitation of motor skills.

\section{Discussion}

According to the results of the observation, the assumption that Japanese children's creation of space in their drawings was due to the national curriculum was rejected. In the elementary school in Japan, teaching the concept of space and the techniques of creating space in drawings was not required in the national curriculum. This means that most children never learn the techniques of creating space through art education of the national curriculum in Japan. Then how do Japanese children learn unique patterns of creating space in drawings and why do they draw in particular ways?

There are some possible reasons beyond the national curriculum One possibility is the classroom orientation. Unlike the US, where children are encouraged to solve problems individually, Japanese children are encouraged to think about problems in a group. Through conversation with peers, children tend to solve problems relatively easily and quickly (e.g. how to create space in 2-D surfaces). Another possibilitv is the Japanese aesthetic. Golomb (1992) says that each culture has a different type of aesthetic when they create spatial presentation. Finally, the third possibility is the big influence from Japanese cartoons, called "Manga" in Japanese. Many researchers mention that the influence of Manga appears in Japanese children's pictorial worlds, especially on figures in their drawings. However, the influence of Manga was not only on 


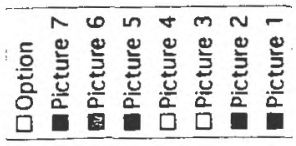

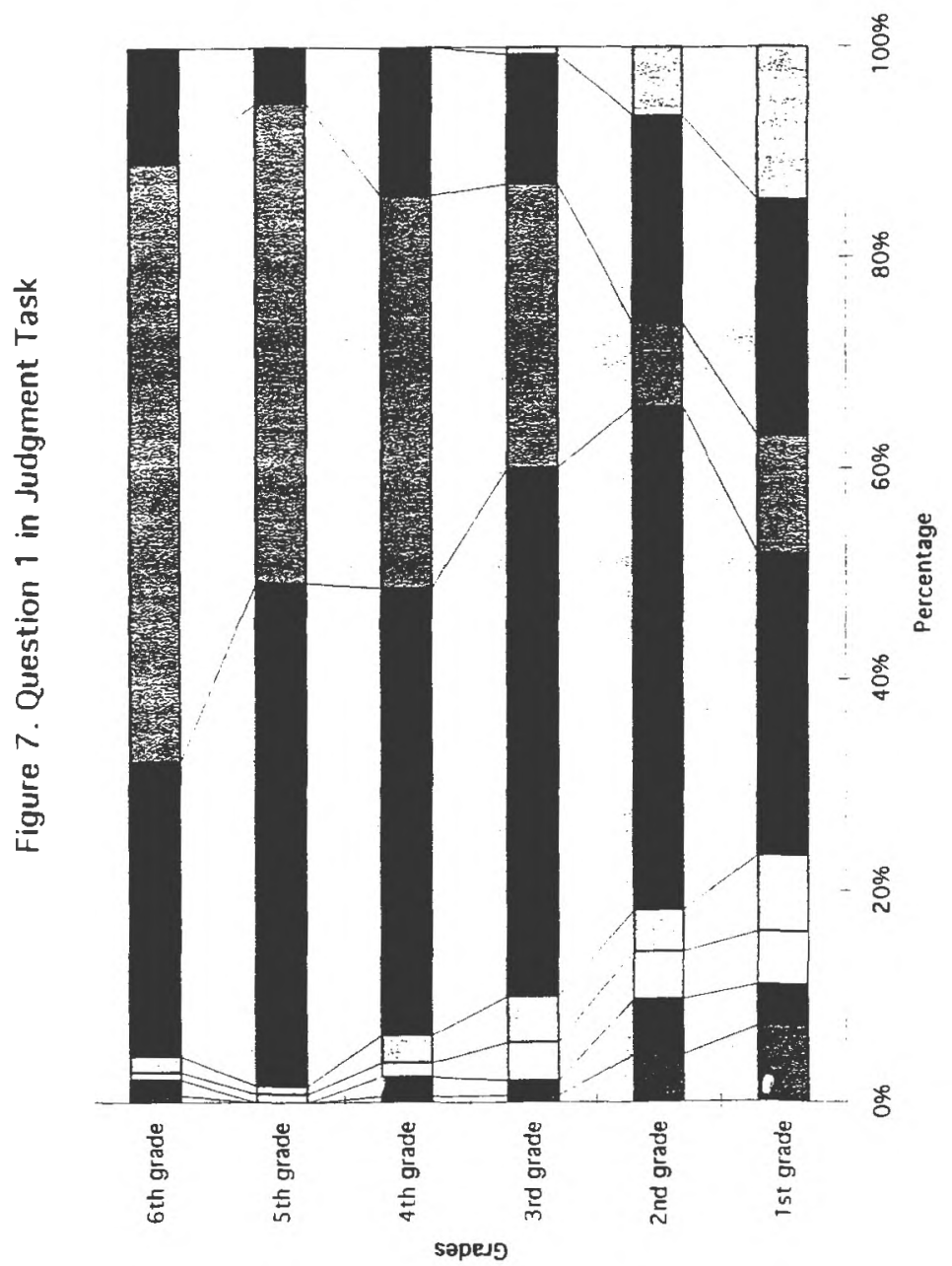



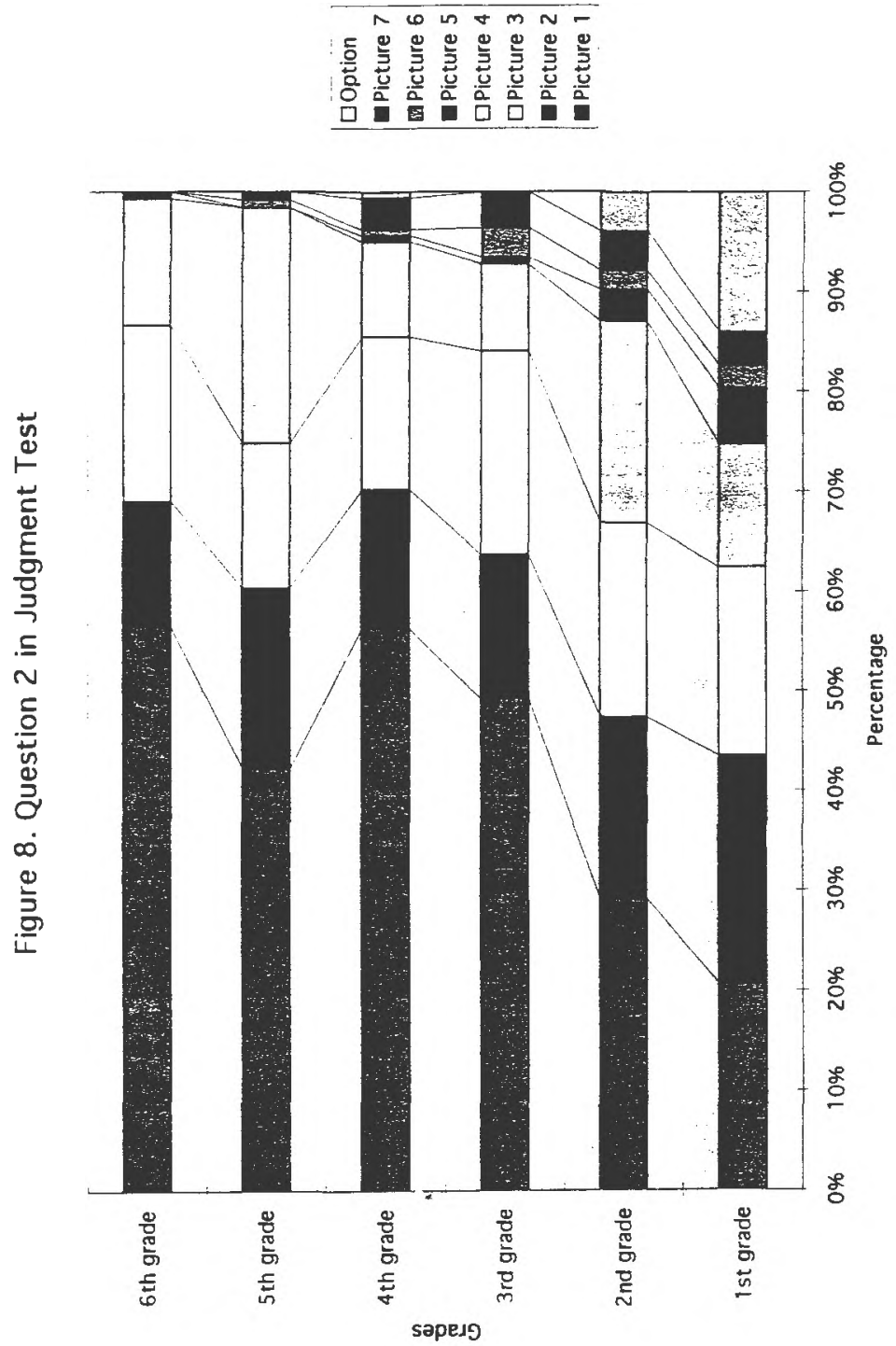

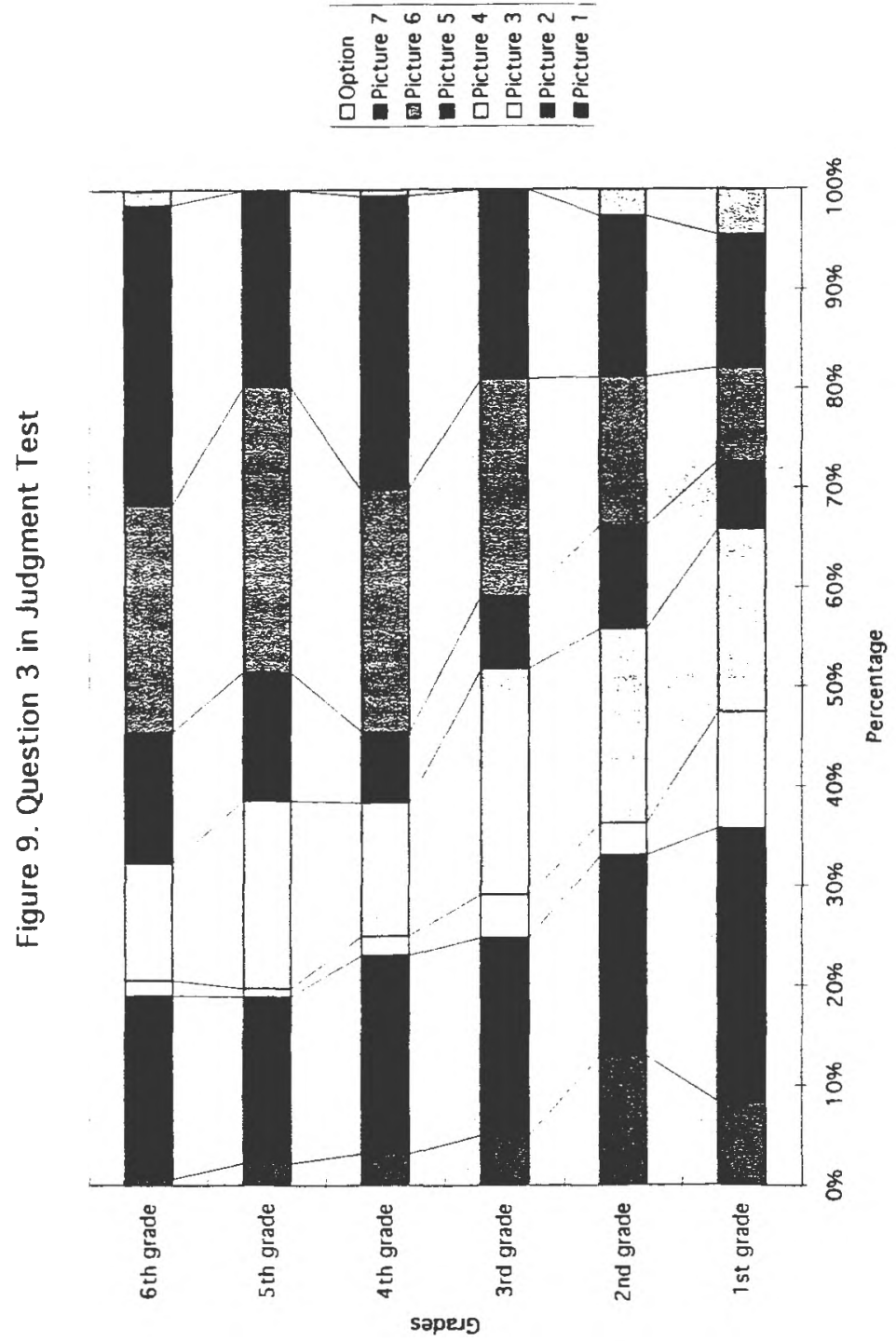


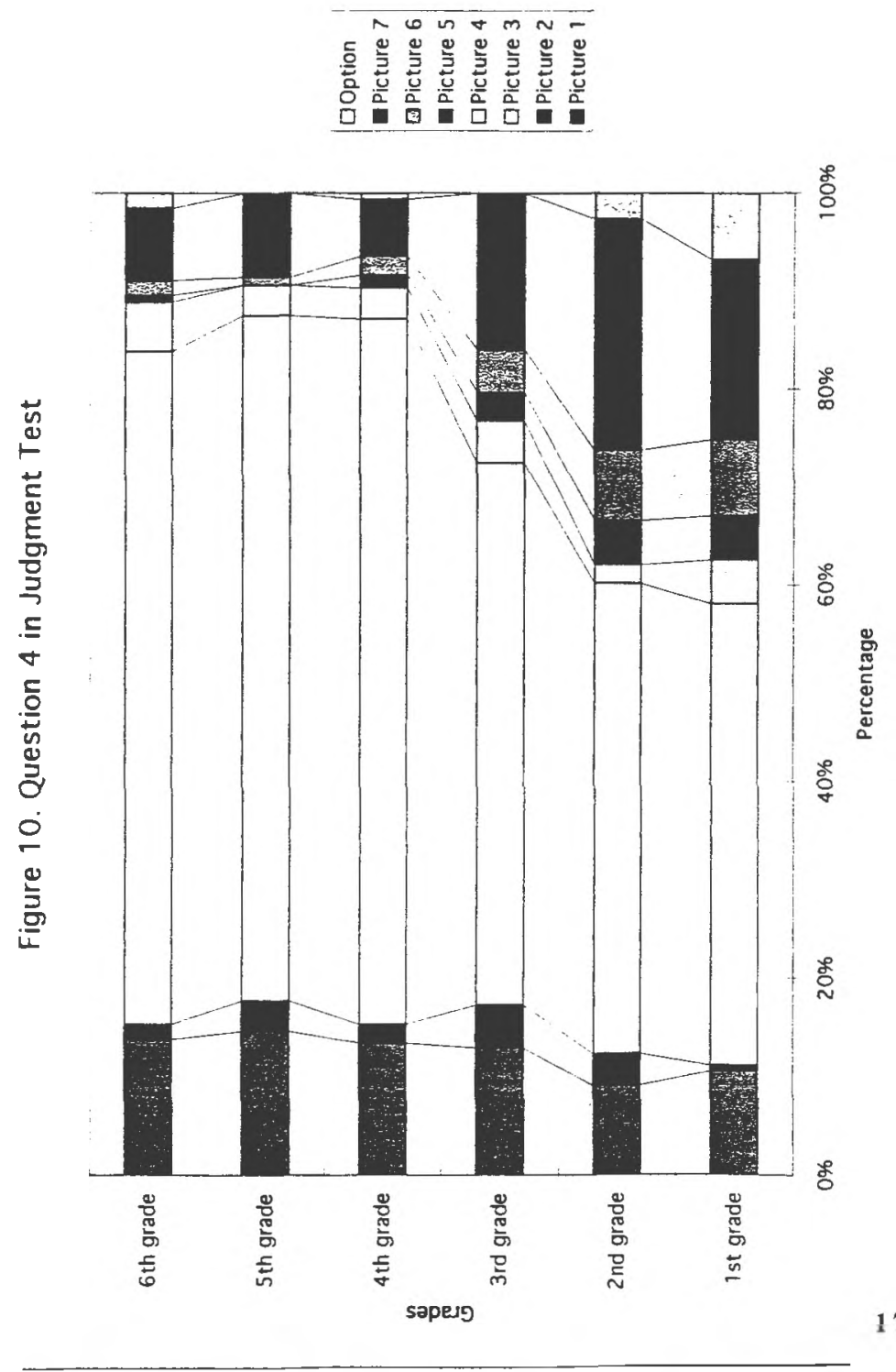

179

Marilyn Zurmuehlen's Working Papers In Art Education 1996-1997 


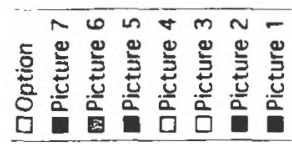

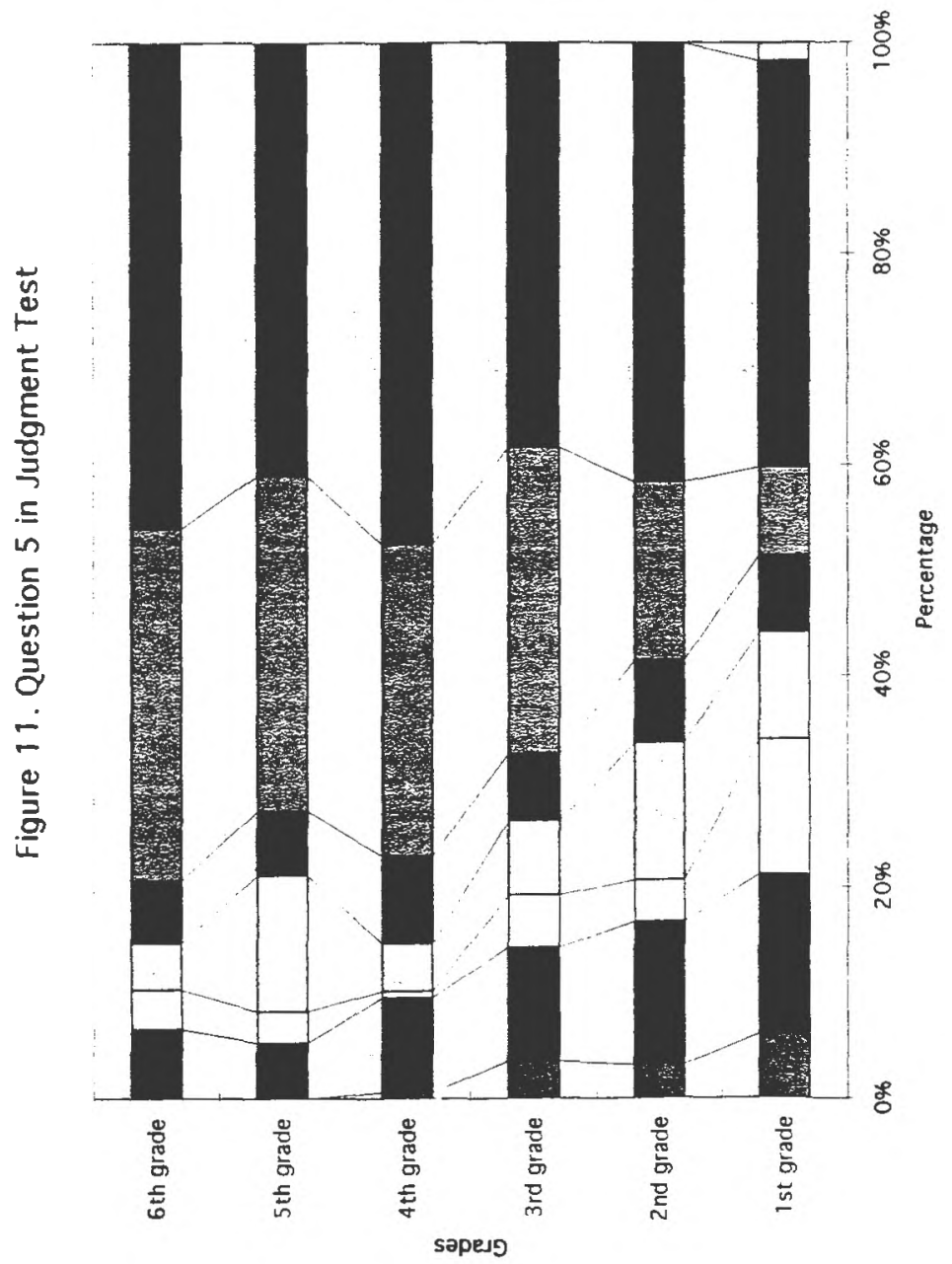

180

Marilyn Zurmuehlen's Working Papers In Art Education 1996-1997 

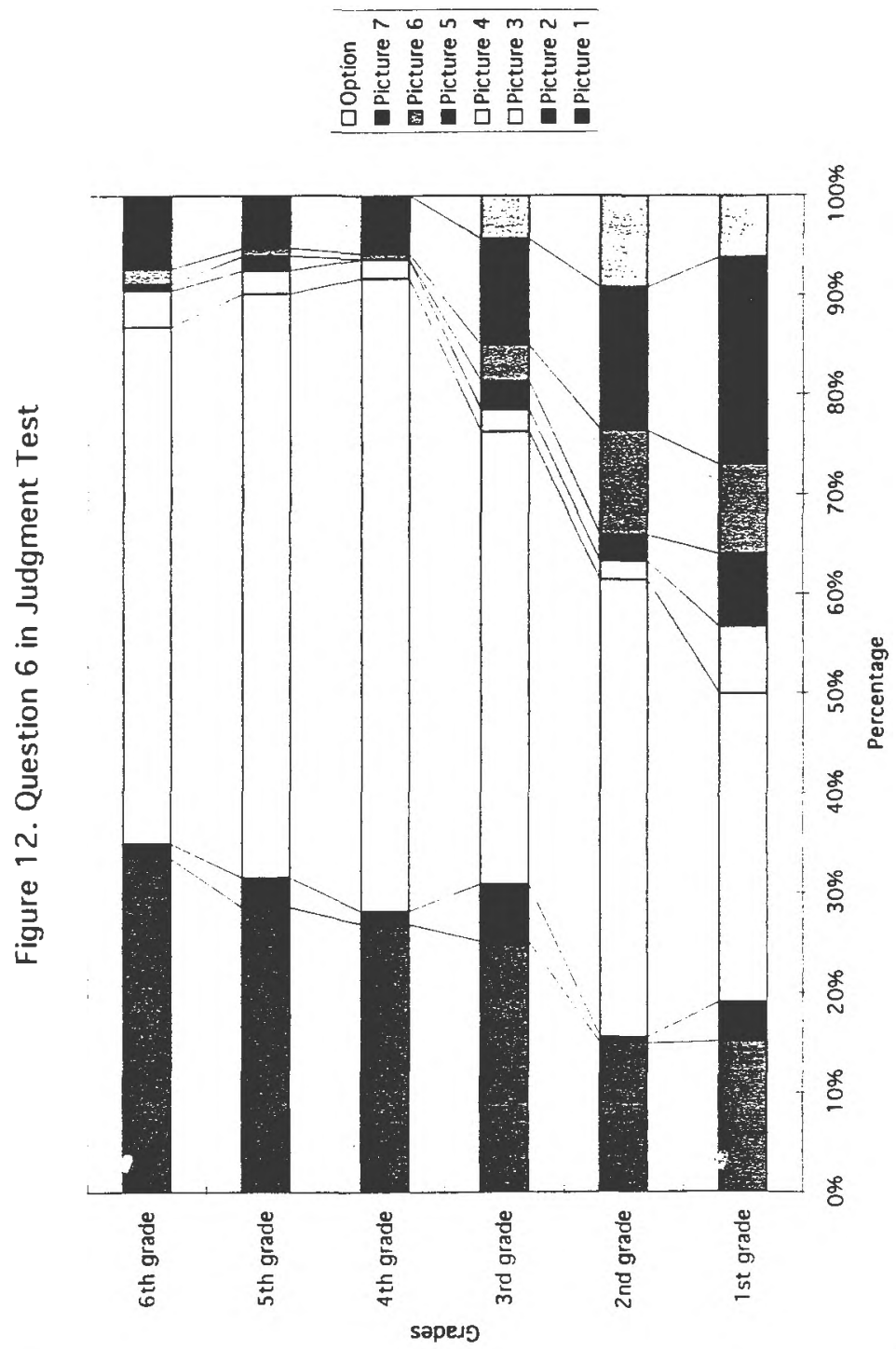

Marilyn Zurmuehlen's Working Papers In Art Education 1996-1997 
figures, but also on the creation of space, since one of Japanese Manga's char acteristics is the complexity of background depicted in the drawings. Manga is not just in comic books in Japan. Manga is aiready a part of Japanese culture. Through the pictorial creations of Manga, children learn how to draw and how to create space on 2-D surfaces, but not from teachers, and not from the art curriculum itself.

As another possibility, some researches tend to easily conclude that characteristics which appear in Japanese children's drawings are due to the infiuence of Japanese traditional art such as the bird's eye views of screen painting and the exaggerated views of Ukiyo-e painting. Those Japanese traditional arts might influence the spatial treatment in Japanese children's drawings; however, these influences cannot be main factors. If Japanese children's characteristics are a result of Japanese traditional arts, the same kinds of characteristics should have emerged for a long time in Japanese children's drawings. I could not often find such tendencies in Japanese children's drawings as early as 30 years ago. Assuming some strong socio-cultural influences have caused the appearance of these Japanese children's drawing characteristics since that time is more likely than ascribing these characteristics to the influences of Japanese traditional arts.

\section{Conclusion}

Bruner (1996) says that all development is undoubtedly not free from culture. Nevertheless, Cole (1996) argues that there is no theory which explains how a particular culture affects cognitive development in a particular direction. It might be true since it is very difficult to define what is the particular socio-cultural factor which causes a particular direction of children's cognitive development. The process of cultural development is not so simple that a conclusion cannot easily be reached. However, it is also true that it is relatively easy to find some socio-cultural characteristics which appear in children's artistic development in a particular culture. The problem is that we cannot determine what the main socio-cultural influences that cause such characteristics are.

The purpose of my research is to challenge Cole's argument. One of my research goals is to find what particular cultural factors cause such characteristics as appear in Japanese children's techniques in spatial treatment in their drawings that the US children seldom use. In addition, how the particular cultural influence. which mainly appears only in Japanese children's drawings, may possibly expand to other children who belong to different cultures in other Asian countries. I am eager to try to construct a "map" of cultural expansion. If I can find a clue of the map of cultural expansion based on my research, which is "spatial treatment in children drawings," it may be possible to predict how a particular cultural factor tends to spread to other cultures. Also, this might lead to the creation of proper art educational curricula to support and encourage uhildren's cognitive and artistic development as well as their interests and preferences. 


\section{References}

Alland, A. (1983). Playing with form: Children draw in six cultures. New York: Columbia University Press.

Arnheim, R. (1954). Art and visual perception. Berkeley: University of California Press.

Arnheim, R. (1969). Visual Thinking. Berkeley and Los Angeles: University of California Press.

Bruner, J. (1990). Acts of meaning. Cambridge, MA: Harvard University Press

Bruner, J. (1996). The culture of education. Cambridge, MA: Harvard University Press.

Cole, M. (1996). Cultural psychology: A once and future discipline, 69 - 83. Cambridge, Massachusetts, and London, England: The Belknap press of Harvard University Press.

Eisner, E.W. (1967). A comparison of developmental drawing characteristics of culturally advantaged and culturally disadvantaged children. Project No. 3086 (US. Dept. of Health, Education, and Welfare, Office of Education, Bureau of Research, September 1967.

Eisner, E.W. (1972). Educating artistic vision. (pp. 126 - 134). New York: The Macmillan Company.

Feldman, D. H. (1980). Beyond universals in cognitive development. NJ: Ablex Publishing Corporation.

Gardner, H. (1980). Artful scribbles: the significance of children's drawings. New York: Basic Books.

Golomb C. (1992). The child's creation of a pictorial world. Berkeley: University of California Press

Goodnow, J. (1977). Children Drawing. Cambridge. MA: Harvard University Press.

Hardiman, G. W. \& Zernich, T. (1988). Some considerations of Piaget's cognitive - structuralist Theory and children's artistic development. Discerning art: concepts and issues. (pp. 355 - 365).Champaign, IL: Stipes Publishing Company.

Hatano, G., Inagaki, K. \& Oura, Y. (1993). Changing Conceptions of Development and Their Implications for Art Education. The bulletin of The 
Faculty of Education, Chiba University, vol. 41 (pp.137-153). Chiba University Press.

I, B. (1995). Spatial representation in drawing: The influence of size, viewpoint, and observation on drawing development. Dissertation paper of University of lllinois at Urbana-Champaign.

Kellogg, R. (1969). Analyzing children's art. Palo Alto, CA: Mayfield.

Lowenfeld, V. \& Brittain, W.L. (1970). Creative and mental growth. (5th ed). NY: Macmillan.

Peak, L. (1991). Learning to go to school in Japan: The transition from home to preschool life. Berkeley: university of California Press.

Piaget, J. \& Inhelder, B. (1956). The child's conception of space. London; Routledge \& Kegan Paul.

Piaget, J. (1962). Comments on Vygotsky's critical remarks concerning the language and thought of the child and judgment and reasoning in the child. Cambridge, MA:M.I.T. Press.

Piaget, J. (1969). The mechanisms of perception. NY: basic Books.

Read, H. (1958). Education through art. New York: Pantheon Books.

Sameroff, A.J. (1989). Principles of development and psychopathology. Sameroff, A.J. \& Emde, R.N. (Eds.), Relationship disturbances in early childhood: A developmental approach. New York: Basic Books.

Smith, N.R. (1993). Experience and art. (2nd ed) New York: Teachers College Press.

Toku, M. (1997). Cross-cultural analysis of artistic development: drawings by US and Japanese children. Art Education, 18, 165-175. Tokyo: Art Education Association Press.

Vygotsky, L.S. (1962). Thought and language. Cambridge, MA.; M.I.T., Press.

Vygotsky, L.S. (1978). Mind in Society. Cambridge, MA: Harvard University Press

Wilson, B, \& Wilson, M. (1982). Teaching children to draw: A guide for teachers and parents. Englewood Cliffs, NJ: Prentice-Hall.

Wertsch, J.V. (1985). Vygotsky and the social formation of mind. Cambridge, MA: Harvard University Press. 